\title{
Albinism with haemorrhagic diathesis: Hermansky-Pudlak syndrome
}

\author{
P E KINNEAR' AND E G D TUDDENHAM ${ }^{2}$
}

From the 'Genetic Clinic, Moorfields Eye Hospital, London, and the ${ }^{2}$ Katherine Dormandy Haemophilia and Haemostasis Unit, Academic Department of Haematology, Royal Free Hospital, London

SUMMARY Four cases of albinism with haemorrhagic diathesis (Hermansky-Pudlak syndrome) are presented. The cases displayed wide phenotypic variation. Electroretinography was performed on all four patients and was found to be normal. One patient developed a cutaneous malignant melanoma.

Albinism associated with a haemorrhagic diathesis and the systemic accumulation of a ceroid-like substance (the Hermansky-Pudlak syndrome) was first described in detail in two albinos who suffered recurrent attacks of bleeding.' It has since been reported in diverse ethnic populations, and about 200 cases have now been reported or are known to exist. ${ }^{2}$ Although rare, it is particularly prevalent in Puerto Ricans, and there is a higher than average incidence in people from southern Holland. ${ }^{3}$ The condition is inherited as an autosomal recessive trait, but in common with other rare recessive conditions it may show pseudodominance in populations with a high gene frequency.

We report here four cases which demonstrate the wide phenotypic expression of this condition and include electroretinographic (ERG) studies, the techniques having been fully described previously. ${ }^{4}$ One of the patients developed a cutaneous malignant melanoma.

\section{Case reports}

\section{CASE 1}

A 38-year-old female presented with marked generalised hypopigmentation, reduced visual acuity, and photophobia (Fig. 1). She has always bruised easily, and she bled excessively during appendicectomy and after dental extractions. In 1964 she underwent ligation of an external carotid artery in an attempt to control recurrent and severe epistaxis. The epistaxis continued subsequently, but appeared to be controlled by oestrogen therapy. In 1978 she underwent

Correspondence to Mr P E Kinnear, FRCS, Genetic Clinic, Moorfields Eye Hospital, City Road, London EC1V 2PD. surgery to remove an acoustic neuroma. Her parents are unrelated, and a younger brother is unaffected.

Her visual acuities are 6/60 in each eye. She has an obvious horizontal nystagmus and an esotropia. Her blue irides are markedly translucent (Fig. 2) and she

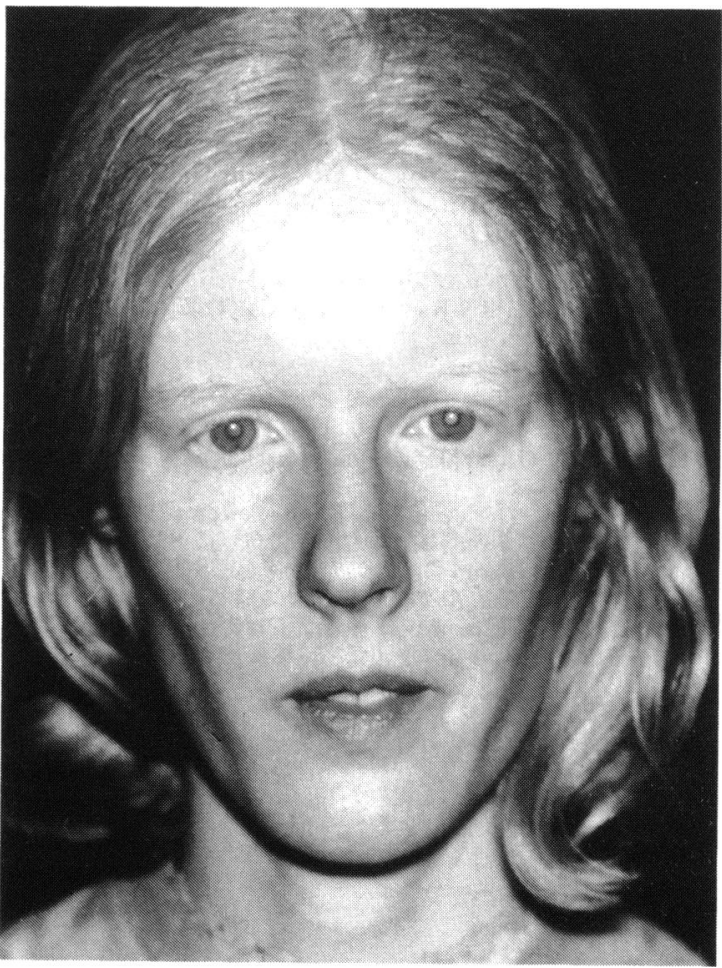

Fig. 1 Case 1. Generalised hypopigmentation characteristic of an albino. 


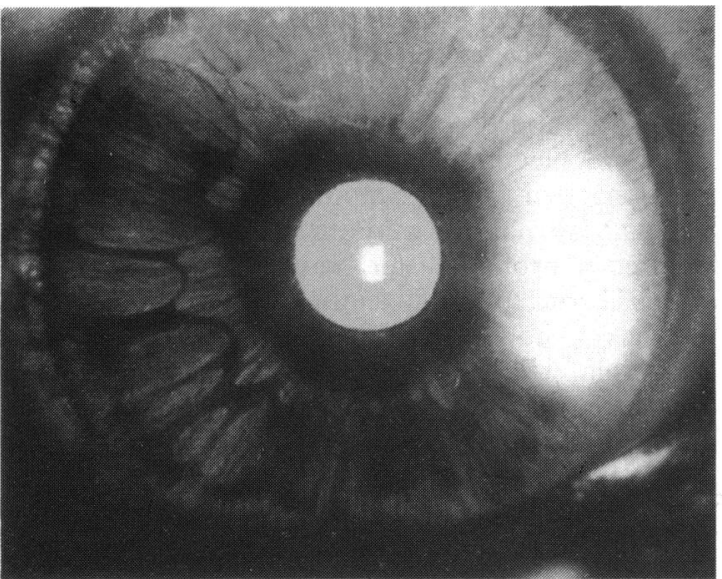

Fig. 2 Case 1. The irides are markedly translucent.

does not have any discernible fundus pigmentation. Her ERG showed normal responses.

This case has previously been reported. ${ }^{56}$ She was found to have a platelet storage pool defect with prolonged bleeding time and abnormal aggregation studies. The bone marrow was examined, but no ceroid pigment inclusions were found within macrophages. Mackie and his coworkers' reported the use of platelet transfusion, cryoprecipitate, and factor VIII concentrate to achieve haemostasis during the surgery for removal of the acoustic neuroma.

\section{CASE 2}

A 29-year-old female of southern Italian extraction with light brown skin and dark brown hair had reduced visual acuity and photophobia. She had bruised very easily all her life. After dental extraction bleeding usually continued for 24 hours, and bleeding continued for a week after tonsillectomy at the age of 9 years. Her parents are first cousins and she has one sister with the same condition (case 3 ).

Her corrected visual acuities are $6 / 60$ in each eye. She has hypermetropic astigmatism, horizontal nystagmus, and marked esotropia. Her irides are brown with moderate translucency and her fundi are hypopigmented. Her single stimulus ERG showed normal oscillatory potentials.

Her template bleeding time was prolonged, with normal prothrombin time (PT), partial thromboplastin time with kaolin (PTTK), and platelet count. There was a severe platelet release defect with low ADP and increased ATP/ADP ratio (adenosine tri-/diphosphate). Bone marrow studies were not performed.

\section{CASE 3}

The 23-year-old sister of case 2 is of similar colouring,

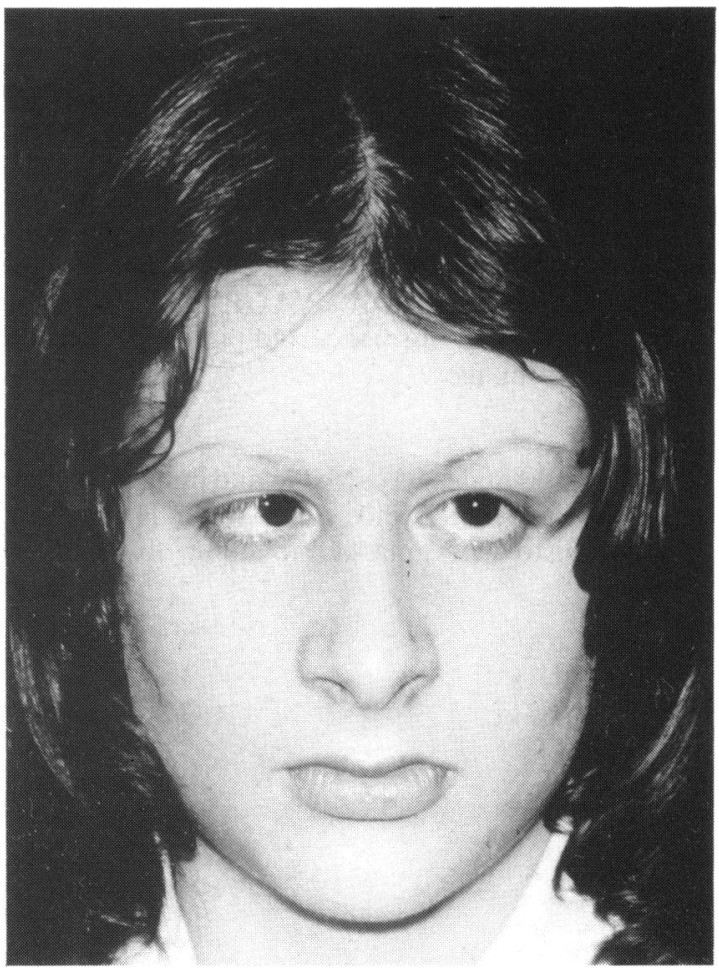

Fig. 3 Case 3. The skin and hair are lighter than is usual in Southern Italians, and an esotropia is present.

with light brown skin and dark brown hair (Fig. 3), and has a reduced visual acuity and photophobia. She has suffered from marked spontaneous bruising all her life.

Her corrected visual acuities are $6 / 60$ in each

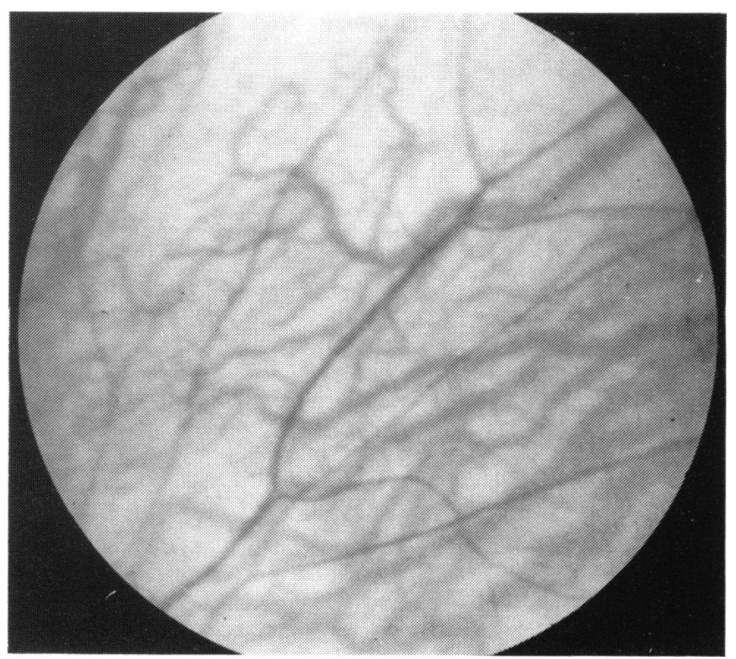

Fig. 4 Case 3. The hypopigmented fundus. 
eye. She has hypermetropic astigmatism, horizontal nystagmus, and esotropia. Her irides are brown, with moderate translucency, and her fundi are hypopigmented (Fig. 4). Her single stimulus ERG showed normal oscillatory potentials.

Her template bleeding time was prolonged. Her PT, PTTK, and platelet count were within normal limits. A platelet release defect was present, with low ADP and an increased ATP/ADP ratio. Her bone marrow showed abnormal ceroid pigment inclusions within macrophages.

CASE 4

A 58-year-old male has pale skin and light blond hair, reduced visual acuity, and photophobia. He has had a life-long history of a marked tendency to bleed. He bleeds for at least 24 hours after dental extraction. In 1960 he underwent excision of a malignant melanoma of his leg with block dissection of the regional lymphatic nodes; surgery was prolonged owing to excessive bleeding. $\mathrm{He}$ is in good health with no pulmonary or bowel symptoms. A chest $x$-ray was normal. His parents were unrelated, and he has an unaffected brother, sister, and two daughters.

His corrected visual acuities are $6 / 60$ in each eye. He has a moderate horizontal nystagmus and an exotropia. His irides are hazel and are markedly translucent. He has no discernible fundus pigmentation. His single stimulus and flicker ERGs were normal, with normal oscillatory potentials. (Fig. 5).

His template bleeding time was prolonged, and his PT and PTTK were within normal limits. A marked
Fig. 5 Case 4. Normal single stimulus and flicker ERGs are present, as are normal oscillatory potentials.
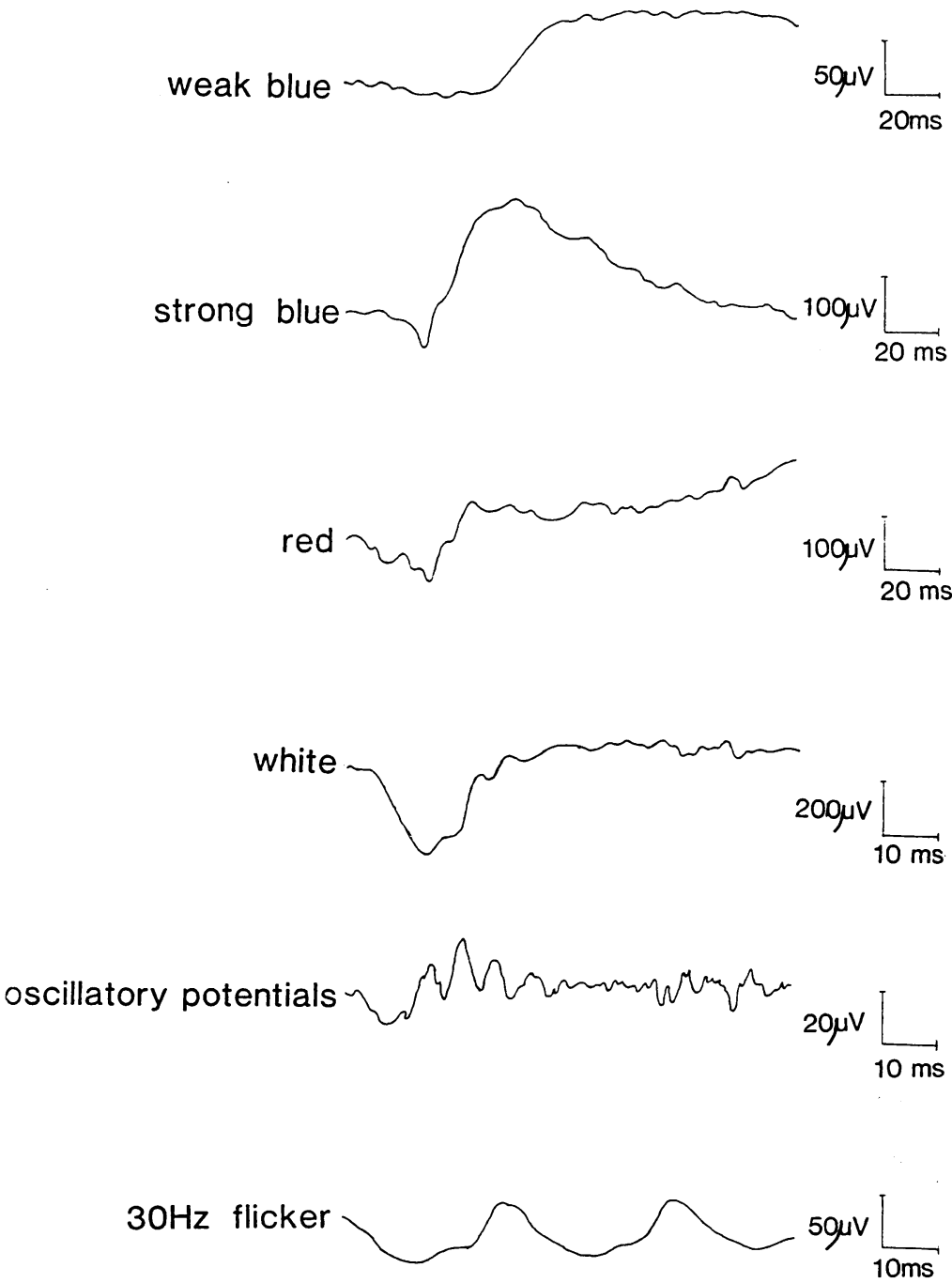
platelet release defect, associated with deficient storage pool ADP, was present. Bone marrow studies showed occasional pigment laden macrophages.

\section{Discussion}

The Hermansky-Pudlak syndrome is one of the tyrosinase-positive forms of oculocutaneous albinism. ${ }^{8}$ There is wide variation in the phenotypic expression of the condition, which is largely dependent on the constitutional (racial) pigmentary background of the individual. The four cases presented-vary from the typical appearance of an albino (case 1, Fig. 1) to the dark haired sisters (cases 2 and 3, Fig. 3) who would not readily be recognised as being albinos. Garay and his coworkers' reported that four of their cases, all Puerto Ricans, had been treated at various teaching hospitals without the diagnosis of albinism being made.

The ocular features of this condition are similar to those of the more common form of tyrosinasepositive oculocutaneous albinism. ${ }^{10}$ There is markedly reduced visual acuity, nystagmus, and a high incidence of strabismus. The irides are translucent, the fundi hypopigmented, and foveal hypoplasia is present.

The bleeding diathesis is usually mild and is commonly brought to notice by dental extraction. However, several fatalities from haemorrhage have been reported. ${ }^{311}$ The diathesis is due to a platelet defect of the storage pool type. ${ }^{6}$ There is an absolute deficiency of dense bodies within platelets, the dense bodies being storage organelles for nucleotides and serotonin. The platelets fail to undergo the release reaction, and therefore there is no secondary phase of irreversible aggregation. ${ }^{12}$ Aspirin and related drugs such as indomethacin, which also impair platelet aggregation, should be avoided by these patients, as a mild bleeding tendency may be exacerbated..$^{13}$

A third part of the triad is the accumulation of ceroid-like material in reticuloendothelial cells and other tissues. ${ }^{1314} 15$ The recently reported pulmonary and gastrointestinal manifestations of this condition are probably related to this abnormal accumulation within tissues. The development of restrictive lung disease in the third and fourth decades due to a fibrosing alveolitis has been reported by various authors. ${ }^{91617}$ An ulcerative form of colitis has been reported in Puerto Rican patients with this condition. ${ }^{918}$

Abnormal electroretinographic findings have been reported in two cases with the Hermansky-Pudlak syndrome. ${ }^{19}$ It was suggested that the reduced rod and cone responses may have been caused by accumulation of the ceroid-like material within the retina. The ERGs in our four patients were normal.
We are therefore unable to confirm the previous report. ${ }^{19}$ This may be due to underlying genetic diversity in otherwise phenotypically similar cases.

There have been several reports of malignant melanomas developing in patients with albinism ${ }^{20.25}$ Witkop et al. ${ }^{2}$ consider that melanomas may not have a higher incidence in albinos than in the general population. We here report a malignant melanoma in a patient with the Hermansky-Pudlak syndrome (case 4).

We are indebted to Professor Barrie Jay for encouragement in studying these patients, and to Professor G B Arden for advice on the retinal electrophysiological studies.

\section{References}

1 Hermansky F, Pudlak P. Albinism associated with hemorrhagic diathesis and unusual pigmented reticular cells in the bone marrow: report of two cases with histochemical studies. Blood 1959; 14: 162-9.

2 Witkop CJ Jr, Quevedo WC Jr, Fitzpatrick TB. Albinism and other disorders of pigment metabolism. In: Stanbury JB, Wyngaarden JB, Fredrickson DS, eds. The metabolic basis of inherited disease. 5th ed. New York: McGraw-Hill, 1983: 301-46.

3 Witkop CJ Jr, White JG, King RA. Oculocutaneous albinism. In: Nyhan L, ed. Heritable disorders of amino acid metabolism. New York: Wiley, 1974: 177-261.

4 Arden GB, Carter RM, Hogg CR, et al. A modified ERG technique and the results obtained in $X$ linked retinitis pigmentosa. Br J Ophthalmol 1983; 67: 419-30.

5 Hardisty RM, Hutton RA. Bleeding tendency associated with new abnormality of platelet behaviour. Lancet 1967; i: 983-5.

6 Hardisty RM, Mills DCB, Ketsa-Ard K. The platelet defect associated with albinism. Br J Haematol 1972; 23: 679-92.

7 Mackie I, Bull H, Brozovic M, Hussein M. Hermansky-Pudlak syndrome and factor VIII ristocetin cofactor. Br J Haematol $1979 ; 41: 449-51$.

8 King RA, Witkop CA Jr. Hairbulb tyrosinase activity in oculocutaneous albinism. Nature 1976; 263: 69-71.

9 Garay SM, Gardella JE, Fazzini EP, Goldring RM. HermanskyPudlak syndrome: pulmonary manifestations of a ceroid storage disease. Am J Med 1979; 66: 737-47.

10 Simon JW, Adams RJ, Calhoun JH, Shapiro SS, Ingerman CM. Ophthalmic manifestations of the Hermansky-Pudlak syndrome (oculocutaneous albinism and hemorrhagic diathesis). Am J Ophthalmol 1982; 93: 71-7.

11 Theuring F, Fielder J. Todliche Blutung nach Zahnextraktion Beitrag zum Hermansky-Pudlak-Syndrome. Dtsch Stomatol 1973; 23: 52-5.

12 White JG, Witkop CJ Jr. Effects of normal and aspirin platelets on defective secondary aggregation in the Hermansky-Pudlak syndrome: a test for storage pool deficient platelets. Am J Pathol 1972; 68: 57-66.

13 Witkop CJ Jr, Hill CW, Desnick S, et al. Ophthalmologic, biochemical, platelet, and ultrastructural defects in the various types of oculocutaneous albinism. J Invest Dermatol 1973; 60: 443-56.

14 Bednar B, Hermansky F, Lojda Z. Vascular pseudohemophilia associated with ceroid pigmentophagia in albinos. Am J Pathol $1964 ; 45$ : 283-94.

15 Bednar B, Jirasek A. Cerebral ceroidosis in albinos. Pathol Eur $1968 ; 3: 341-6$.

16 Davies BH, Tuddenham EGD. Familial pulmonry fibrosis associated with oculocutaneous albinism and platelet function defect. A new syndrome. $Q J$ Med 1976; 45: 219-32. 
17 Hoste P, Williams J, Devriendt J, Lamont H, Van Der Straeten M. Familial diffuse interstitial pulmonary fibrosis associated with oculocutaneous albinism. Report of two cases with a family study. Scand J Respir Dis 1979; 60; 128-34.

18 Schinella RA, Greco A, Barton LC, Denmark LW, Cox RP. Hermansky-Pudlak syndrome with granulomatous colitis. Ann Intern Med 1980; 92: 20-3.

19 Fagadau WR, Heinemann MH, Cotlier E. Hermansky-Pudlak syndrome: albinism with lipofuscin storage. Int Ophthalmol $1981 ; 4:$ 113-22.

20 Wood C, Graham D, Willsen J, Strefling A. Albinism and amelanotic melanoma: occurrence in a child with positive test results for tyrosinase. Arch Dermatol 1982; 118: 283-4.
21 Albert LI, Damjanov I. Malignant melanoma in an albino: diagnosis supported by ultrastructure. Mt Sinai J Med (NY) 1977; 45: 447-50.

22 Witkop CJ Jr. Albinism. In: Harris H, Hirschhorn K, eds. Advance in human genetics. New York: Plenum Press, 1971: 2: 61-142.

23 Bhende YM. Malignant amelanotic melanoma of skin in albino. Indian J Med Sci 1952; 6: 755-9.

24 Young TE. Malignant melanoma in albino. Arch Pathol Lab Med 1957; 64: 186-91.

25 Garrington GE, Scofield HH, Cornyn J, Lacey GR. Intraoral malignant melanoma in a human albino. Oral Surg 1967; 24: 224-30. 